\title{
Is there hope in improving 5-year overall survival? - review of 5-year overall survival data from KEYNOTE-001
}

\author{
Wisdom Akingbemi, Edward Garon \\ Department of Hematology-Oncology, David Geffen School of Medicine at UCLA, Los Angeles, CA, USA \\ Correspondence to: Edward Garon, MD. 2020 Santa Monica Blvd, Suite 600 Santa Monica, CA 90404, USA. Email: EGaron@mednet.ucla.edu. \\ Provenance and Peer Review: This article was commissioned and reviewed by the Section Editor Dr. Song Xu (Department of lung cancer surgery, \\ Tianjin Medical University General Hospital; Tianjin Key Laboratory of Lung Cancer Metastasis and Tumor Microenvironment, Lung Cancer \\ Institute, Tianjin, China). \\ Response to: de Silva M, Itchins M, Pavlakis N. Breakthrough 5-year survival with pembrolizumab in Keynote-001 study: horizon shifting in advanced \\ non-small cell lung cancer with immune check point inhibition. Ann Transl Med 2020;8:555. \\ Bironzo P, Passiglia F, Novello S. Five-year overall survival of pembrolizumab in advanced non-small cell lung cancer: another step from care to \\ cure? Ann Transl Med 2019;7:S212. \\ Cohen AY, Kian W, Roisman LC, et al. Are we facing a cure in lung cancer?-KEYNOTE-001 insights. Ann Transl Med 2019;7:S215.
}

Submitted Apr 17, 2020. Accepted for publication May 11, 2020.

doi: $10.21037 /$ atm-2020-95

View this article at: http://dx.doi.org/10.21037/atm-2020-95

We would like to thank the editorial authors for commenting on, "Five-Year Overall Survival for Patients with Advanced Non-Small-Cell Lung Cancer Treated With Pembrolizumab: Results from the Phase I KEYNOTE-001 Study".

The KEYNOTE-001 study clearly demonstrated safety and efficacy of pembrolizumab in patients with advanced non-small cell lung cancer (NSCLC) when it was originally reported in 2015 (1). As Cohen et al. clearly suggest, the intervening years show that the field has made great advances, indicated by far superior outcomes when compared to the time of cytotoxic chemotherapy and early targeted therapies were the only available systemic treatments. The updated analysis from KEYNOTE-001 show that 5 -year overall survival (OS) for treatment-naïve and pre-treated patients was about $15 \%$ (vs. $<6 \% 5$-year OS of the pre-immunotherapy era) (2). As Cohen et al. also note, the combination of pembrolizumab and platinumdoublet chemotherapy in subsequent phase 3 trials has become a standard-of-care therapy following the results of KEYNOTE-189 (3).

Bironzo et al. discussed factors that predict survival. In classifying the results of KEYNOTE-001 based on PDL1 expression levels, we see that OS for patients with PDL1 tumor proportion score (TPS) of at least 50\% was twice as long as that for patients with PD-L1 TPS of $1-49 \%$ (4).
The editorial authors also note correctly that these results were replicated with another PD-1 inhibitor, nivolumab, in the BMS CA209-003 trial (5). While the OS rates are no doubt astounding compared to the therapies that preceded it, we see that most patients do not derive these durable benefits.

As KEYNOTE-001 shows, certain factors or challenges influence efficacy outcomes in patients with advanced NSCLC getting immunotherapy. Patients with primary resistance to checkpoint inhibitors (CPIs) do not respond to the initial therapy. Skoulidis et al., highlight STK11/LKB1 mutations as an important predictor of primary resistance to anti-PD-1 therapy in KRAS-mutant adenocarcinoma of the lung (6). PD-L1 TPS was used as a criterion in subsequent phase 3 pembrolizumab monotherapy trials such as KEYNOTE-010, KEYNOTE-024 and KEYNOTE042 (7). Low or no PD-L1 is probably the best-studied mechanism of primary resistance, predicting poor 5-year OS outcomes in KEYNOTE-001 for instance (2).

Acquired resistance occurs at a later time, suggesting that the tumor and/or immune cells evolve or change after an initial response. Some of the mechanisms for acquired resistance include loss of $\mathrm{T}$ cell function, lack of $\mathrm{T}$ cell recognition by suppression of tumor antigen presentation. Another mechanism of acquired resistance that has been well documented in advanced melanoma is loss of the 
shared component of HLA class I, molecules, B2M (8). Furthermore, there are immune inhibitory checkpoints (or pathways) that prevent antitumor response in patients receiving immunotherapy. Studies are being conducted across varying malignancies including advanced NSCLC to determine effective antibodies against these inhibitory pathways (9).

As the editorial authors speculate, more research on combinatorial therapies might be the way forward in moving from care to cure-or at least, improving the current 5-year OS rates.

\section{Acknowledgments}

Funding: None.

\section{Footnote}

Conflicts of Interest: Both authors have completed the ICMJE uniform disclosure form (available at http://dx.doi. org/10.21037/atm-2020-95). EG reports personal fees from Dracen Pharmaceuticals, grants and personal fees from EMD Serono, personal fees from GSK, grants and personal fees from Novartis, grants from AstraZeneca, grants from Genentech, grants from Bristol-Myers Squibb, grants from Merck, grants from Eli Lilly, grants from Iovance, grants from Neon, grants from Dynavax, grants from Mirati, outside the submitted work. WA has no conflicts of interest to declare.

Ethical Statement: The authors are accountable for all aspects of the work in ensuring that questions related to the accuracy or integrity of any part of the work are appropriately investigated and resolved.

Open Access Statement: This is an Open Access article distributed in accordance with the Creative Commons Attribution-NonCommercial-NoDerivs 4.0 International License (CC BY-NC-ND 4.0), which permits the noncommercial replication and distribution of the article with the strict proviso that no changes or edits are made and the original work is properly cited (including links to both the formal publication through the relevant DOI and the license). See: https://creativecommons.org/licenses/by-nc-nd/4.0/.

\section{References}

1. Garon EB, Rizvi NA, Hui R, et al. Pembrolizumab for the treatment of non-small cell lung cancer. N Engl J Med 2015;372:2018-28.

2. Garon EB, Hellmann MD, Rizvi NA, et al. Five Year Overall Survival for Patients With Advanced Non-SmallCell Lung Cancer Treated With Pembrolizumab: Results From the Phase I KEYNOTE-001 Study. J Clin Oncol 2019;37:2518-27.

3. Cohen AY, Kian W, Roisman LC, et al. Are we facing a cure in lung cancer? - KEYNOTE-001 insights. Ann Transl Med 2019;7:S215.

4. Bironzo P, Passiglia F, Novello S. Five-year overall survival of pembrolizumab in advanced non-small cell lung cancer: another step from care to cure? Ann Transl Med 2019;7:S212.

5. Topalian SL, Hodi FS, Brahmer JR, et al. Five-Year Survival and Correlates Among Patients With Advanced Melanoma, Renal Cell Carcinoma, or Non-Small Cell Lung Cancer Treated With Nivolumab. JAMA Oncol 2019;5:1411-20.

6. Skoulidis F, Godlberg ME, Greenwalt DM, et al. STK11/ LKB1 Mutations and PD-1 Inhibitor Resistance in KRAS-Mutant Lung Adenocarcinoma. Cancer Discov 2018;8;822-35.

7. Incorvaia L, Fanale D, Badalamenti G, et al. Programmed Death Ligand (PD-L1) as a Predictive Biomarker for Pembrolizumab Therapy in Patients with Advanced Non-Small Cell Lung Cancer (NSCLC). Adv Ther 2019;36:2600-17.

8. Zaretsky JM, Garcia-Diaz A, Shin DS, et al. Mutations Associated with Acquired Resistance to PD-1 Blockade in Melanoma. N Engl J Med 2016;375:819-29.

9. Hellmann MD, Paz-Ares L, Bernabe Caro R, et al. Nivolumab plus Ipilimumab in Advanced Non-Small-Cell Lung Cancer. N Engl J Med 2019;381:2020-31.
Cite this article as: Akingbemi W, Garon E. Is there hope in improving 5-year overall survival?-review of 5-year overall survival data from KEYNOTE-001. Ann Transl Med 2020;8(11):728. doi: 10.21037/atm-2020-95 